\title{
EL PSOE ALICANTINO DURANTE LA GUERRA CIVIL
}

\author{
FRANCISCO MORENO SÁEZ
}

Se ha señalado con mucho acierto (1) que el estallido de la guerra civil en julio de 1936 no supuso ningún hecho relevante en la historia interna del PSOE, salvo una cierta pausa impuesta por la necesidad de atender a las necesidades urgentes planteadas por la sublevación militar. EI PSOE llegaba a la contienda muy dividido internamente. Santos Juliá ha descrito el proceso de disgregación interna de los socialistas españoles, que remonta a 1934, aunque cuenta con antecedentes en los años de la Dictadura de Primo de Rivera. Si en los inicios de la República se perfilaban tres sectores, tradicionalmente denominados como derecha, centro e izquierda y ligados respectivamente a las figuras de Besteiro, Prieto y Largo Caballero, a partir de 1934 se asiste a una clara radicalización, al menos verbal, en el seno del Partido: el sector de Besteiro es relegado casi totalmente y la lucha queda centrada entre los sectores de Largo Caballero y Prieto, divididos en relación con las perspectivas políticas que se abrían para el socialismo tras la Revolución de Asturias, las alianzas que habría que intentar y, cosa fundamental, el control del movimiento socialista en su conjunto, tras la separación de las ejecutivas del PSOE y de la UGT. Lo que en este proceso hay de lucha por el poder interno en el PSOE no se ha subrayado debidamente y se ha hecho, en ocasiones, demasiado caso a las proclamas sin tener en cuenta los hechos. Muchas de las actitudes adoptadas por uno $u$ otro sector no tienen, por desgracia, más explicación que el hecho de que tal actitud no había sido adoptada por el otro sector o podía significar una mejor posición en el conjunto del movimiento socialista. Y esto, que a nivel estatal puede quedar enmascarado (2) se revela en todo su esplendor cuando descendemos a niveles más localistas. La historia local tiene sus peligros, pero tiene también las ventajas de des-

(1) SANTOS JULIÁ, «De la división orgánica al Gobierno de unidad nacional», en Socialismo y guerra civil. Editorial Pablo Iglesias. Madrid. 1987.

(2) Y.que ha sido enmascarado, sobre todo, por el hecho de que, hasta hace poco tiempo, se ha aceptado por los historiadores de la guerra civil la historia que los protagonistas hicieron para justificar sus posiciones: de ahí, la tradicional descalificación de Lamoneda y Negrín como «traidores" al socialismo, actitud hoy ya en revisión a partir de algunos trabajos, como los de SANTOS JULIÁ, "Partido contra sindicato: una interpretación de la crisis de mayo de 1937", y HELEN GRAHAM, «EI Partido Socialista en el poder y el gobierno de Juan Negrín», en el libro ya citado sobre Socialismo y guerra civil. 
velar una realidad mucho más pedestre (3). El hecho geográfico -que en la España que quedó en poder de la República no se encontraban todos los partidarios de la República ni todos los allí residentes eran partidarios de la República, sino que existian muchas personas indiferentes, cuando no hostiles, que hubieron de adaptarse a las circunstancias- es otro elemento que ha sido frecuentemente olvidado en los estudios sobre la guerra civil y que, lógicamente, demuestra toda su importancia cuando se desciende al nivel local. Tampoco, por citar otro hecho que trataremos de desarrollar en este artículo, ha sido suficientemente puesto de relieve el papel jugado por los parlamentarios y lo que podríamos llamar el «aparato» de la UGT y el PSOE, que debió de ser muy determinante en las actitudes que tomaban las Agrupaciones y sindicatos locales, actitudes que eran, por consiguiente, bastante menos espontáneas de lo que se supone. En suma, el estudio de la evolución del PSOE en un contexto local -en este caso, la provincia de Alicante-permite matizar mucho la visión general y comprender mejor que no eran muchas veces las ideas las que movían a unos y otros, sino intereses mucho más a ras de tierra.

EI PSOE alicantino no se había distinguido demasiado - salvo por la presencia en algún Congreso de José Verdes Montenegro, que abandonaría el Partido con ocasión del pleito de las Internacionales, o Rafael Millá, que pasaría después al PCE - por su criticismo en relación con el aparato del Partido. La Agrupación más numerosa existente - al menos hasta bien entrada la Dictadura-, la de Elche, se caracterizaba por una absoluta sumisión a las directrices emanadas de Madrid y la falta total de espíritu crítico: en realidad, cuando comenzaron las discrepancias fue porque la crítica había comenzado ya en los niveles dirigentes del Partido, nunca de forma autónoma. En los años de la Dictadura, la creación en Alicante de la Oficina de Reclamaciones permitió a los socialistas extender por la provincia una importante organización sindical y, en menor medida, política que se caracterizaba por la prudencia de su comportamiento. En 1931 Alicante contaba con 22 agrupaciones -el quinto lugar entre las provincias de España - y consiguió en las elecciones cuatro alcaldes (Elche, Crevillente, Petrel y Cocentaina), siendo la primera provincia española en este terreno (4).

(3) Por ejemplo, no estaría de más preguntarse, en estos temas de la guerra civil, cómo era posible que - como se ha venido admitiendo durante tanto tiempo aceptando ciertos mitos - unos campesinos, analfabetos en su inmensa mayoria, sin la menor tradición sindical ni experiencia política, fuesen capaces de la noche a la mañana de llevar a la práctica unas teorías que, por cierto, tampoco estaban tan desarrolladas, sobre la producción y distribución más justa de los bienes materiales.

(4) SALVADOR FORNER, Industrialización y movimiento obrero, Alicante 1923-1936. Instituició Alfons el Magnánim. Valencia. 1982. 
La línea predominante en el PSOE alicantino sólo comenzaría a cambiar en los primeros meses de la República: antes, era la cercana a Besteiro -y ello se debía, tanto al papel jugado en esa Oficina de Reclamaciones por el maestro gallego Manuel González Ramos, como a la tradicional relación con la provincia de Andrés Saborit-y por eso, dos de los primeros diputados alicantinos, González Ramos y Rodríguez de Vera, eran de esa tendencia, aunque Rodolfo Llopis era caballerista. La decepción que para muchos socialistas supuso el hecho de que no se produjesen los necesarios cambios en la sociedad española a pesar de la presencia de los socialistas en el poder en el bienio 1931-1933 - decepción tanto mayor en las localidades más pequeñas, donde se había podido contemplar cómo seguian mandando, ahora bajo el gorro frigio, los mismos caciques de la Monarquía, con la colaboración de la Guardia Civil- impulsó una radicalización en las bases socialistas que, y esto no siempre ha sido bien comprendido, era poco auténtica: es decir, no era revolucionaria, sino consecuencia del incumplimiento de las reformas (5). Parece evidente que esa era la convicción predominante en la mente de los miembros del aparato político y sindical socialista: realmente, pensar que hombres como Largo Caballero y la mayoría de los funcionarios del Partido o Sindicato que le seguian eran revolucionarios no dejaría de ser injusto con personas tan moderadas siempre, pero que también sabían captar casi siempre lo que las bases querían.

$Y$ esas bases estaban desesparadas por la insospechada resistencia que las clases dominantes, sobre todo, a nivles locales, ofrecian a la política reformista de la coalición republicano-socialista desde los primeros meses de la República. Hubo entonces entre los socialistas una ofensiva verbal contra esa reacción - a la que también contribuyó el miedo a la amenaza fascista, que estaba imponiéndose en Europa - tal vez con la intima esperanza de que esas clases dominantes recapacitasen y volviesen a negociar, aceptando la necesidad de elevar el nivel de vida del proletariado. En realidad, más que pretender una República socialista, lo que se buscaba era una auténtica República

(5) Esta mentalidad, por cierto, contaba con antecedentes en la provincia de Alicante: por ejemplo, en la ăctitud de los socialistas ilicitanos ante la Revolución Rusa: cuando llegan las noticias de la toma del poder por el proletariado en el lejano pais de los Zares a unos socialistas de escasa formación, empeñados en dura lucha con los caciques locales y atentos sobre todo a preservar, en malas condiciones, un aparato sindical, se acepta la teoria y se enaltece a la Revolución, pero cuando se intenta trasladar esa Revolución a la práctica no aparecen más que propuestas reformistas, porque no sabían hacer otras. $Y$ así se llega a decir en el semanario socialista ilicitano Trabajo que la mejor forma de conseguir los Soviets es votar en unas manipuladísimas elecciones municipales... Igualmente, en muchas de las críticas que al capitalismo y a la monarquia se hacen en los años posteriores a la guerra europea, subyace el deseo de que las clases dominantes comprendan la necesidad de las reformas para que no haya que llegar a una Revolución que, en el fondo, no se desea. 
burguesa progresista; más que a implantar "nuestra dictadura», a lo que se aspiraba era a que no hubiera ninguna dictadura. Porque lo que resulta impensable es que esa dictadura del proletariado o esa Revolución que se proclamaba la pudieran hacer personas tan reformistas como la mayoría de los dirigentes socialistas y ugetistas: asi se demostraría cuando llegase al poder, ya en plena guerra civil, Largo Caballero, a pesar de contar con la colaboración de la CNT y la UGT. Por otra parte, en muchas de las críticas a la presencia de los socialistas (no olvidemos que uno de ellos era Largo Caballero) en el Gobierno en esos primeros meses de la República subyacía la postura abstencionista del grupo de Besteiro y Saborit. Que esa radicalización tenía algo de verbalismo lo demuestra - a pesar de que, como ha señalado Forner, se produjesen ciertas maquinaciones caciquiles en algunas comarcas para evitar el triunfo de Villalta y Salvador García, afines al sector caballerista- el hecho de que en 1933 el PSOE alicantino siguiese contando con Llopis, González Ramos y Rodríguez de Vera como diputados, es decir, los mismos que en 1931: en última instancia, la propia presentación de González Ramos y Rodríguez de Vera demuestra el peso todavía grande del sector besteirista.

Sin embargo, hay que reconocer que, al menos a nivel de declaraciones y artículos en la prensa, acuerdos de Congresos y otras manifestaciones, en 1933 y 1934 se observa en la provincia de Alicante esa radicalización, esa exigencia de ir hacia una revolución de clase, aún a costa de la ruptura del Partido (6). La actitud del gobierno contribuyó sobremanera al triunfo de esta opción, pues en la primavera de 1934 se produjeron numerosos incidentes en la provincia que parecian dar la razón al sector caballerista, partidario de las Alianzas Obreras. Sin embargo, una nueva prueba de ese verbalismo lo tenemos en la escasa incidencia en Alicante de la huelga de octubre de 1934, que, por cierto, acabó triunfando, ¿paradójicamente?, en las bases prietistas, mientras que la «radicalizada» Agrupación madrileña se mantenía a la espera. A lo largo de 1935 y en las difíciles condiciones en que la reacción derechista había colocado a las Agrupaciones Socialistas (7), se consuma el pro-

(6) SALVADOR FORNER, o.c., ha recogido varias muestras de la radicalización de la prensa socialista alicantina entre 1931 y 1934: "Lo que nosotros deseamos es apoderarnos del poder para que la revolución se haga en un sentido neto, sin mezcla, con nuestro contenido ideal y material» (El Mundo Obrero, 26-XII-1931). «Atrás pues los timoratos, los demócratas y los legalistas; que dimitan, si no quieren consumar la traición a los trabajadores, los que sueñan con reconstruir la alianza republicano-socialista, que claman otra vez los que son responsables de esta situación. Ahora más que nunca somos un partido de CLASE y OBRERO. Que se aparten los que tengan miedo a estas dos palabras. Que no estorben. ¡Proa hacia la Revolución Socialista! „Paso franco a la insurrección!» (El Mundo Obrero, 13-1-1934.

(7) Son muy frecuentes, en la correspondencia de las Agrupaciones alicantinas con la Ejecutiva nacional - y a la que pertenecen cuantas cartas citaremos en este trabajo, conservadas 
ceso de control del aparato del Partido en Alicante por el sector que lideraba a nivel provincial Rodolfo Llopis, mediante la expulsión de González Ramos de la Agrupación alicantina por haber escrito algunos artículos en Democracia, el órgano de la tendencia besteirista, y una moción de censura contra Rodríguez de Vera. El II Congreso de la Federación Provincial Socialista alicantina, celebrado en octubre de 1935, acordó propuestas tan aparentemente diversas como la colaboración con los republicanos (postura que defendía el sector de Prieto) y la unidad del proletariado marxista español (propuesta por el sector caballerista). En las elecciones de febrero de 1936 los cuatro diputados socialistas elegidos pertenecian ya al sector «izquierdista» y eran Llopis, Villalta, Ginés Ganga y Salvador Garcia Muñoz.

Después de las elecciones de 1936, la actitúd de enfrentamiento entre los sectores caballerista y prietista del Partido perjudicó enormemente al PSOE y a la propia República. Para Largo Caballero y sus seguidores, había que acceder al poder cuando se agotasen las posibilidades de los republicanos (por ello no apoyaban un gobierno de coalición y se opusieron a que Prieto formase gobierno) y desde la legalidad republicana avanzar hacia el socialismor mediante la unidad con los comunistas -entonces, no hay que olvidarlo, un partido minúsculo que se pensaba poder absorber con cierta facilidad: de ahí, el apoyo caballerista a la fusión de las Juventudes y la entrada de los sindicatos comunistas en la UGT-y la unidad sindical con la CNT. Para los prietistas, lo ideal era un gobierno de coalición entre socialistas y republicanos, con el apoyo del PCE y la CNT (8).

en la Fundación Pablo Iglesias y cuyas fotocopias se encuentran en el Instituto «Juan Gil-Albert» de Alicante - las solicitudes de condonación de cuotas aludiendo a la persecución sufrida a manos de los caciques locales tras octubre de 1934. Así, la Agrupación Socialista de Sagra describe muy gráficamente las penalidades sufridas desde entonces: el 6 de octubre les fue clausurado el local y «nos perseguían a muerte», pasando «meses y meses sin darnos un misero jornal sólo porque somos socialistas y como somos pobres quieren rendirnos a la fuerza», ya que "a los que defienden la causa obrera en estos pueblecitos, nos tratan peor que a perrosw. Y la Agrupación de lbi afirma que en el movimiento de octubre «encarcelaron a casi todos sus afiliados, y al que no apresaron, fue represaliado y expulsado de su puesto de trabajo, pero hemos aguantado sin desmayo, esperando el triunfo, del que teniamos seguridad».

(8) De la magnitud del enfrentamiento interno existente en la primavera de 1936 en el PSOE nos puede dar una idea la lectura, de entre las muchas muestras existentes, de dos comunicaciones de Agrupaciones de pequeñas localidades alicantinas a la Ejecutiva Nacional del Partido, absolutamente impensables en otras circunstancias: la AS de Muro de Alcoy, en carta del 6-junio-1936, desautoriza pura y llanamente al Comité Nacional del Partido y se adhiere a la táctica caballerista con estas palabras: “Nosotros entendemos en la hora presente, que el PSOE no debe cobijar caciques feudatarios por que (sic), habiendo ya pasado a la. Historia Fernandina, es el Escorial, con toda su pompa fúnebre, el albergue más adecuado para esos hombres antes que los rústicos bancos de una Casa del Pueblo». Y la Agrupación de Benejúzar, sancionada por su actitud favorable a Largo Caballero, niega pura y simplemente a la Ejecutiva del PSOE la «autoridad moral para realizar el programa de nuestro glorioso Partido». 
La guerra civil no modificó sustancialmente esa situación del PSOE, aunque el vacío de poder que se dio en la España republicana en las primeras semanas y el papel que, tanto en la economía como en la propia guerra, con sus milicias, jugaban ahora los sindicatos, puso a la CNT y a la UGT en condiciones de tomar el poder revolucionariamente, cosa que - como ha señalado Santos Juliá- no hicieron porque no podian hacerlo, precisamente por ser unos sindicatos. Lo que sucedió fue que, a través del Gobierno de Largo Caballero, los sindicatos ostentaron la hegemonía en la España republicana, lo que impulsó a la Ejecutiva del PSOE a buscar un acercamiento al PCE -ahora fortalecido por su capacidad organizativa, el apoyo de la URSS a la República, que, por cierto, contrastaba con la indiferencia de la Internacional Socialista ante el destino de la España leal, y por la propia división interna del PSOE - para contrarrestar lo que se consideraba excesivo papel de los sindicatos. En realidad, el gobierno de Largo Caballero no llevó a cabo una política revolucionaria, sino de unidad nacional para lograr la victoria en la guerra aunque, desde luego, no avanzó nada en esa unidad con la CNT o con el PCE que el sector «izquierdista» del PSOE proclamaba: en el fondo, vino a hacer la política que propugnaba el sector centrista.

Todo este proceso, ¿cómo fue entendido a nivel local, donde, como se sabe, era más bien escaso el conocimiento de la teoría? En unas localidades donde el hecho de la guerra civil había forzado a una mayoría de obreros, hasta entonces al margen de toda actividad política y sindical, a adoptar medidas y soluciones para resolver problemas cotidianos y dónde la adscripción a uno u otro sindicato dependía, muchas veces, de la tradición o de la presencia de un dirigente prestigioso, $-y$ por tanto, mucho más la adscripción a una u otra «tendencia» en el interior del PSOE-, donde se interpretaba al pie de la letra determinadas proclamas unitarias, donde se veía el transcurrir de la guerra a través de una prensa condicionada por la censura y por el simplismo, en esas localidades la posición política de cada una de sus Agrupaciones - por mucho que la lectura de algunos comunicados a la Ejecutiva parezca abonar una independencia de criterio rayana a veces en la pura indisciplina, fruto de la división interna- era, básicamente, mimética y dependía muy especialmente de la actitud que tomase el «aparato» del Partido y del Sindicato - que, por cierto, a niveles locales seguía siendo, como era tradición en el socialismo español, el mismo aunque a nivel nacional apareciesen enfrentados, enfrentamiento que no constituía, por más justificaciones teóricas que, haciendo de là necesidad virtud, se lanzasen, más que el resultado de la lucha de tendencias- y de la minoría parlamentaria, por su papel de conexión entre la cúpula del Partido, -en este caso, la «tendencia», porque el Partido en sí mismo no existía- y las distintas Agrupaciones. 
Tras los primeros meses de guerra, donde la actividad frenética subsumió las diferentes posturas en un afán de unidad y resistencia contra el fascismo, la convicción de que la guerra iba a ser larga replanteó muchas cuestiones. La prudente actitud del PSOE de no enviar, en esos primeros meses, carnets a las Agrupaciones locales «hasta en tanto no pasen las presentes circunstancias» no pudo evitar la entrada en masa de nuevos afiliados, forzados muchas veces a la integración en algún Partido. Así, el PSOE en la provincia de Alicante pasó de 2.433 afiliados en julio de 1936 a 6.952 en diciembre de 1937, triplicando prácticamente sus miembros y extendiéndose a toda la provincia. Por mucho posible entusiasmo antifascista que supongamos en gentes hasta entonces apartadas de la política, es evidente que en muchas de esas afiliaciones había bastante de oportunismo y, sobre todo, grandes dosis de ignorancia de la teoría marxista o de la historia del socialismo español, más allá de cierta cultura básica obrera que probablemente sí que estaba bastante extendida, pero que era común a todos los obreros, estuviesen encuadrados en la CNT o en la UGT.

Ya en 1937, el 7 de marzo, el Pleno del Comité Provincial de la Federación Provincial Socialista (FPS) alicantina convoca un Congreso extraordinario para los días 9 al 11 de abril por cuanto «las circunstancias presentes, de verdadero confusionismo, exigen una determinada aclaración de nuestras posiciones tácticas y una orientación clara a seguir por las Organizaciones de nuestro Partido". Es evidente que en esta convocatoria subyacen ya todas las cuestiones a las que antes hemos hecho alusión y que dividían al Partido: el 3 de abril, la FPS pregunta a la Ejecutiva nacional su opinión ante una propuesta del PCE alicantino para iniciar conversaciones en pro de un trabajo común antifascista y sobre «los puntos encaminados a la fusión de los dos Partidos marxistas en uno sólo», a lo que la Ejecutiva responde recordando su circular que prohibía a las secciones iniciativas de esa índole, lo que no excluía cordiales relaciones con los comunistas. En el Congreso se acordaron por unanimidad unas Conclusiones que muestran cierto eclecticismo: los reunidos aspiran a la implantación del Socialismo mediante el marxismo y la dictadura del proletariado, pero insisten en la necesidad de mantener la República democrática, dirigida por la clase obrera en colaboración con la pequeña burguesia; rechazan un gobierno sindical, pues la UGT y la CNT deben situarse en «su papel de administradores de la economía, dejando a los partidos la actividad política»; acuerdan mantener la colaboración con todas las fuerzas del Frente popular, pero estrechar relaciones con el PCE, debiendo abordarse en un Congreso del PSOE la unificación de ambos Partidos; critican el proselitismo en los frentes y deciden respetar la independencia de la JSU. Los congresistas insistían en que la unificación con los comunistas 
proporcionaría «un consistente bloque antifascista que ayude de una manera contundente a la gestión del Gobierno en torno a la guerra». Sin embargo, se produjeron cambios en la ejecutiva de la FPS alicantina que fueron favorables a la tendencia caballerista. Poco después Antonio Escribano, secretario de Organización alicantino, escribe a la Ejecutiva Nacional para informar que, conforme a los acuerdos suscritos a nivel estatal, han constituido en Alicante un comité de enlace con el PCE para preparar el $1 .{ }^{\circ}$ de Mayo y otras actividades, pero no deja de mostrar su recelo ante los comunistas (9).

Santos Juliá ha interpretado recientemente la crisis de mayo de 1937, que desplazó del poder a Largo Caballero, como un enfrentamiento entre el sindicato y el partido socialista. En el seno del PSOE, ya en 1937, tanto los seguidores de Caballero como los de Prieto propiciaban la «unidad» de los trabajadores españoles, más amplia en el caso de los «izquierdistas» -pues proponian no sólo la constitución de un solo partido marxista con el PCE, sino también la unidad con la CNT-, pero en tales proclamas existía una gran dosis de confusionismo: el mito de la unidad era una desesperada forma de contrarrestar los frecuentes enfrentamientos que en la retaguardia se daban entre los distintos partidos y sindicatos (10). Al propio tiempo, los dirigentes nacionales frenaban las iniciativas locales tendentes a la unidad: de ahí, la insistencia de Lamoneda en prohibir los acuerdos locales con los comunistas, fruto de la ignorancia de la ideología y del hecho de que las masas acababan por creer en los mitos que emitían sus dirigentes (11), por considerar que tales acuerdos, "aún no estando malintencionados», perturbaban la labor de acercamiento entre ambos Partidos. Para los socialistas, el crecimiento del PCE - al que no dejaban de recordar su condición de "recién llegado» al movimiento obrero español-, su prestigio, su propia solidez - frente a las divisiones internas del socialismo-, lo que estaba ocurriendo en la JSU, etc., eran factores que recomendaban prudencia, aún sin llegar a negar lo que las bases, precisamente como consecuencia de las proclamas de los dirigentes, sentían como necesario: la unidad. Los recelos de Largo Caballero ante

(9) Comunica también que, para ver si los comunistas desean realmente la unidad, les han pedido que no mantengan la Federación Provincial Campesina existiendo la Federación de Trabajadores de la Tierra y dado que los demás sindicatos comunistas habían ingresado ya en la UGT.

(10) Esta pugna es observable también en la correspondencia interna del PSOE, por ejemplo, cuando se trata del nombramiento de determinados cargos: véanse así, los esfuerzos de los socialistas alicantinos para que se pusiese al frente del Gobierno Civil a un republicano, pues no eran convenientes ni un comunista ni un socialista, en junio de 1937.

(11) Una Agrupación alicantina pretende colocar en su bandera, junto al yunque socialista, las insignias comunistas, y la de Altea es requerida por la Ejecutiva nacional para que suprima de su papel timbrado la estrella de cinco puntas y coloquen «el yunque que es el emblema del Partido". 
el papel de los comunistas en la defensa de Madrid inclinaron a éstos hacia el sector de Prieto, con el que, el 15 de abril, llegaron a un acuerdo para constituir comités de enlace a todos los niveles. Largo manejó entonces la posibilidad de un gobierno sindical, excitando el recelo tradicional de los libertarios ante «los políticos», lo que a su vez provocó - sin llegar a conseguir avances decisivos en la colaboración con la CNT- un frente común de los partidos republicanos, socialista y comunista que se puso de manifiesto tras los hechos de mayo. Ahora bien, esta interpretación de Santos Juliá resulta menos evidente a niveles locales - aunque se podrá argumentar, con razón, que no era a esos niveles a los que se resolvian las crisis-, donde se pone en cambio de manifiesto la falsedad de muchas de esas propuestas: es la necesidad de encontrar apoyos ante la mejora de posiciones de la tendencia rival la que empuja a Largo Caballero hacia sus tradicionales adversarios libertarios y la que fuerza a sus seguidores a teorizar sobre la conveniencia de un gobierno sindical.

Helen Graham ha señalado también las grandes dosis de retórica existentes en el pretendido revolucionarismo de Largo Caballero, que se limitó desde el poder a hacer la política de Frente Popular que, en la primavera de 1936, había bloqueado. Cuando Negrín aceptó formar gobierno, lo hizo tras consultar a a Ejecutiva del PSOE y mantuvo esa misma política del Frente Popular, pero intentando reducir el papel jugado por los sindicatos, en favor de los partidos y del propio estado. Aumentó entonces la lucha por el poder en el seno del PSOE: las organizaciones socialistas partidarias de Largo se reunieron en Valencia el 28 de mayo de 1937 y pidieron la dimisión de la Ejecutiva por no ser representativa. Obviamente, los miembros de esa tendencia trataron de lograr apoyos para sus posiciones en las bases y así la FPS alicantina envía el 18-junio-1937 a la Nacional los acuerdos tomados por unanimidad y sin abstención alguna en la Conferencia Provincial de secretarios de las Agrupaciones, tras un informe de Rodolfo Llopis. Esos acuerdos ponian a la FPS alicantina en una posición absolutamente enfrentada con la Ejecutiva nacional: habían visto con disgusto su intervención en la crisis «por estimar que no habian sabido interpretar, no ya el sentir de los afiliados al mismo, sino el de las masas antifascistas del país", se solidarizaban con la actuación de Largo Caballero, se negaban a colaborar con el PCE hasta que no hiciese upública rectificación de los conceptos injuriosos vertidos por Jesús Hernández y Pasionaria», acordaron estrechar las relaciones con la CNT para constituir una única central sindical, y excitaban a todos los afiliados para que no se desvirtuase la JSU y perdiese «el espiritu marxista que adquirieron al calor de nuestro Partido". Esos acuerdos aparecen en la prensa de Valencia favorable a Larao antes de llegar a poder de la Ejecutiva (aunque no se 
hizo pública la censura al organismo nacional) y ésta contesta el 8-julio-1937, manifestando su malestar por esos juicios que consideran antirreglamentarios y su extrañeza por «variar radicalmente la orientación que muy recientemente tomó unánimemente vuestro Congreso». Las posiciones están claras y asi se interpretan las tensas relaciones entre ambos organismos. También se evidencia la lucha de tendencias con ocasión de las relaciones de las Agrupaciones Socialistas con la Ejecutiva Nacional (12); las que no eran favorables a la línea caballerista trataban de conectar directamente con la Ejecutiva Nacional, en tanto que la FPS pretendía controlarlas y trataba de aparentar una unanimidad tras sus posiciones que no existía de hecho, como lo demuestra la correspondencia con la Ejecutiva Nacional de las Agrupaciones alicantinas, muchas de las cuales niegan seguir los dictados de la FPS. Otro motivo de fricción fue el nombramiento como Gobernador Civil de la provincia del comunista Jesús Monzón, muy criticado por la FPS y al que dice ser ajena la Ejecutiva Nacional.

El enfrentamiento siguió en el verano de 1937. Como se acordó por el sector caballerista, también en Alicante se procedió a convocar el 22 de julio un Congreso Provincial Extraordinario para el 15 de agosto, donde se informaría de las reuniones de las FPS en Valencia, se criticaría al Comité Nacional del PSOE - que no había aceptado las sugerencias caballeristas, en su reunión del 19 de julio-y se pediría un Congreso extraordinario del Partido para tratar de una serie de temas que afectaban a su vida interna y a sus relaciones con otras organizaciones del Frente Popular. Como es sabido, la Ejecutiva Nacional que dirigían González Peña y Lamoneda procedió, con medidas de fuerza, contra la FPS valenciana, los periódicos caballeristas y la posición «izquierdista» en el seno de la minoría parlamentaria socialista. Todo ello provocó la airada protesta de la FPS alicantina, que el 28-julio-1937 acusaba a la Ejecutiva de no respetar los métodos democráticos «que siem-

(12) La Agrupación de Elda envia en junio de 1937 una carta muy interesante a la Ejecutiva nacional. En ella señalan los perjuicios que los personalismos y la división estaban causando al Partido, ya desde antes del 18 de julio. Por ello, el ideal socialista resultaba quebrantado porque «muchos compañeros y secciones nuestras hay que sólo se inclinan en sus determinaciones hacia lo que opinan determinados camaradas». Para recuperar el puesto que le corresponde por su gloriosa historia, el PSOE debe de abandonar los personalismos y elevar «nuestra conducta y actuación al tono de grandeza que tiene el ideal socialistaw. Asegurañi tras señalar la incongruencia de la creación de la Federación Provincial Campesina cuando ya existía la Federación Española de Trabajadores de la Tierra, que en los pueblos nadie créa en la posibilidad de colaborar con los comunistas y se temía que la unidad con ellos supusiese la desaparición del PSOE. El PCE había conseguido excluir del gobierno a Largo Caballero y umañana será Negrín o Prieto». Por ello, solicitaban de la Ejecutiva que «poseidos plenamente del ideal socialista, os apartéis de toda pasión no os sintáis parte beligerante, que penséis solamente en las ideas socialistas, en nuestro Partido y en los intereses de la guerran. 
pre fueron norma de nuestro glorioso Partidon. Pese a la reacción del sector "centrista», la FPS alicantina se mantuvo en sus posiciones y el 1-agosto un Pleno Provincial aprobó la actuación - por unanimidad, se dijo, pero no era cierto, como denunciaría poco después la AS de Denia (13)- de la Ejecutiva Provincial y mantuvo la feccha del Congreso, al que invitaron a asistir al propio Lamoneda, acordando al mismo tiempo - y de nuevo, rechazando los acuerdos de la Ejecutiva nacional- no reanudar la actividad de los comités de enlace con los comunistas, sino «mantenerlos en suspenso». El Comité Nacional del PSOE les escribe el 6 de agosto diciendo que su actitud «revela que, desgraciadamente, seguis inspirando vuestra conducta en las órdenes de una fracción", les acusa de haber enviado delegados a Murcia y Granada para que suscribiesen protestas contra la Ejecutiva y adhesiones a las reuniones divisionistas habidas en Valencia, y de no respetar los acuerdos anteriores del Congreso Provincial: «Esta actitud de franca rebeldía debe cesar para bien del Partido. Estamos seguros de que los militantes alicantinos no la desean. Desautorizamos, pues, la celebración del Congreso y os requerimos para que lo suspendáis». La Ejecutiva nacional señalaba agudamente la inconsistencia de ciertas posiciones izquierdistas al decir que lo importante era la actividad de una tendencia, que "el año pasado se basaba en una filia comunista y este año se basa en una fobia comunista". Al propio tiempo, se dirigía el Comité Nacional a las Agrupaciones de la provincia conminándoles a que no acudiesen al Congreso.

El 18 de agosto el Comité Provincial de Alicante se quejaba ante el $\mathrm{Na}$ cional de que su prohibición anulaba «la autonomía que siempre tuvieron nuestras organizaciones dentro de la Organización Nacional del Partido». Por ello, aplazaba hasta el 22 el Congreso y seguía insistiendo en sus críticas a «las equivocadas decisiones" de la Ejecutiva y Comités Nacionales y reclamando un Congreso extraordinario del Partido «para solventar definitivamente la cuestión interna del Partido». Lamentaban también que la última carta del Comité Nacional se hubiera publicado en la prensa comunista antes de llegar a sus manos (14). En definitiva, y después de muchas discusiones epistolares sobre qué debía de ser la disciplina, la Comisión Ejecutiva del PSOE prohíbe taxativamente el Congreso Provincial y envía una carta a las Agrupaciones locales pidiendo que no asistan «si desean permanecer dentro de la discipli-

(13) La Ejecutiva muestra su agrado por la actitud de los socialistas de Denia en carta de 6 de agosto de 1937: "Veíamos con dolor que la mayoría de las Agrupaciones de Alicante, incluso veteranas, permanecían insensibles al desfiguramiento descarado de los acuerdos de vuestro Congreso".

(14) Véase la similitud de estas quejas con las anteriores del Comité Nacional sobre la publicación de notas «izquierdistas» en la prensa valenciana. 
na del Partido». En Avance -diario que había aparecido el 3 de agosto de 1937 porque «ahora es preciso forjar un estado de opinión enmarcado en una línea ajustada a la realidad", es decir, porque había que reforzar la tendencia caballerista (15) - se puede seguir el proceso de resistencia de la FPS a la Ejecutiva nacional: hay numerosos artículos, recuadros y notas argumentando sobre la necesidad de construir antes la unidad interna socialista, por medio de un Congreso extraordinario,para proceder luego a la unidad con los comunistas (16), se colma de elogios a Largo Caballero (al que se califica de "símbolo auténtico de la unidad del proletariado españo(»), se polemiza constantemente con Nuestra Bandera y se denuncia el hecho de que Lamoneda y González Peña hayan estado en Alicante y no hayan visitado ningún Centro Obrero ni Socialista, sino únicamnte el Gobierno Civil (17). Al propio tiempo, los parlamentarios alicantinos - Llopis, Villalta y García, junto a Escribano y Galarza- llevan a cabo varios mítines por la provincia (Orihuela, Alcoy, Cocentaina) para trasmitir a las bases las posiciones «izquierdistas». Todo ello, obviamente, aderezado con constantes protestas de luchar por la unidad antifascista. Sin embargo, la presión de la Ejecutiva nacional tuvo éxito y muchas de las Agrupaciones de la provincia anunciaron que no asitirian al Congreso: entre otras, las de Sax, Torrevieja (18), Parcent, San Juan, Orba, Alcoy (19), Monóvar (20), Jijona (21), La Encina (22), Elda, Denia (23). En una reunión del Comité provincial de la FPS, celebrada el 18 de agosto (24) así se reconoce: la circular de la Ejecutiva nacional quebrantó «la unidad interna del Partido que existía en la provincia» y por ello se aplazó el Congreso (25). Sin embargo, no disminuian las reticencias hacia la Ejecutiva nacional y en el citado pleno del comité Provincial se justifica la definitiva suspensión por la necesidad de no hacerse «cómplices de los manejos divisionistas de la Ejecutiva Nacional's.

(15) Hasta la primavera de 1937, socialistas y comunistas venían colaborando en Bandera roja, que sustituyó al Diario de Alicante y al que, en diciembre de 1936, acordaron ambas fuerzas políticas imprimir «una orientación francamente revolucionaria». Pero las tensiones existentes entre ambos partidos llevaron a la aparición, en julio de 1937, del diario comunista Nuestra Bandera y, en agosto, de Avance, en tanto que Bandera roja seguía controlada por los caballeristas, como portavoz que era de la UGT.

(16) "La unidad de los Partidos Socialista y Comunista debe basarse en una plataforma de cordialidad, pues las ideas y la táctica tienen en estos instantes escasos puntos discrepantes». Avance, 5-VIII-1937.

(17) Más aún, es el diario comunista Nuestra Bandera el que publica unas declaraciones de ambos dirigentes socialistas, lo cual no dejaría de tener su lógica, dado el enfrentamiento existente entre dichos dirigentes y la FPS alicantina, pero que al mismo tiempo aumentaba el anticomunismo de los caballeristas.

(18) El acuerdo se toma por unanimidad en la asamblea, cosa lógica «si se tiene en cuenta que esta Agrupación es de las veteranas de la provincia». 
Como es sabido, continuó el enfrentamiento entre centristas e izquierdistas y se produjo entonces la escisión en el seno de la UGT, con la elección de una nueva Ejecutiva que encabezaba González Peña y a la que se oponía la que dirigía Largo Caballero. Los socialistas alicantinos, al menos el «aparato" que controlaba la FPS y la prensa, se alinearon claramente con el sector de Largo Caballero, como era lógico. Tanto Bandera Roja (que era dirigida en esos momentos por Iniesta Cuquerella), como Avance y la revista mensual Spartacus elogian constantemente a Largo Caballero, protestan contra «las maniobras» en el seno de la UGT, publican las adhesiones a la Ejecutiva de Largo Caballero, piden un Congreso extraordinario de la central sindical, reproducen discursos de Largo y declaraciones de Wenceslao Carrillo. Toda esa defensa (26) iba acompañada de ataques al Partido Comunista, invocaciones a Pablo Iglesias, etc. El 16 de octubre, el diario socialista alicantino anunciaba así el discurso que iba a pronunciar el día siguiente en Madrid su líder, Largo Caballero: «Su palabra será, como siempre, clara y concisa. Mentalidad de un marxista que ha vivido desde hace más de cincuenta años el proceso de la Revolución Española, y que sabe que la única salida a la tragedia que vive el pueblo es una revolución que cumpla todas las aspiraciones económicas y sociales de la clase trabajadora». En los días siguientes Avance publica, censurado, el discurso de Largo y anuncia su llegada a Alicante. El 22 de octubre pide a «todos» que acudan «a saludar al secretario auténtico de nuestra gloriosa sindical», a pesar de que «el gobierno ha suspendido los actos públicos. Entre ellos, COMO ES NATURAL, el de Alicante. Largo Caballero, sin embargo, saludará a los trabajadores alicantinos mañana sábado

(19) Que, sin embargo, opinaba que se debía de reunir un Congreso Nacional para resolver «todas las diferencias de criterio en cuanto al pasado, presente y porvenir del Partido desde el movimiento subversivo».

(20) Que aseguraba que wla seriedad de nuestro Partido no debe estar a merced de caudiIlos», en clara alusión a Largo Caballero.

(21) Que critica directamente a Largo por tolerar «con gran error que se especule con su nombre y su historia» y le califica de semidiós envanecido por su excesiva fatuidad.

(22) Que también se pronuncia por un Congreso Nacional para que «volvamos a ser lo que siempre ha sido la gran familia socialista».

(23) «Por considerarlo improcedente y alentador de un acto de indisciplina».

(24) A la que asisten delegados comarcales de Alicante, Almoradí, Elche, Polop, Pedreguer, Jijona, Villajoyosa, Ibi, Callosa d'En Sarriá, Orihuela, Villena, Novelda, Monóvar y Cocentaina.

(25) En Avance, 13-VIII-1937 aparece un «Comentario socialista a la suspensión del Congreson; se debió a que había sido "garantizada una seguridad plena de que la unidad puede encauzarse por derroteros que para nosotros aparecian, hasta hace muy pocas horas, poco menos que intransitables».

(26) Véase, por ejemplo, «La auténtica Ejecutiva de la UGT es la que tiene como secretario a Largo Caballero", en Avance, 2-X-1937. 
y el domingo visitará Elda, Elche y otros pueblos de la provincia. Hoy más que nunca, viva la UGT». (27).

Estas muestras de resistencia caballerista en la provincia de Alicante encontraron una buena expresión en la «Revista de afirmaciones» que la FPS sacaba a la luz con el nombre de Spartacus y que dirigía Ferrándiz Albors. La misma índole de la revista permite, mucho más que la prensa diaria, una mayor explicitación de las posiciones defendidas por los caballeristas en esos momentos; así, en el número 3, de fecha 1 de septiembre de 1937, hay un editorial titulado «Sindicalismo y política", donde se acepta que los sindicatos no deben de llevar la dirección de los asuntos públicos, pues el factor político es el preponderante en la lucha actual (28). Por ello, y aunque la UGT no debe organizarse como fuerza politica, los ugetistas debian «vitalizar al partido, ponerlo a tono con el imperativo de nuestra lucha contra el fascismo, ir a la conquista de los puestos de dirección con los procedimientos democráticos que los estatutos del partido imponen». No cabe formulación más clara de qué era lo importante y qué lo secundario en esta polémica: no tanto un enfrentamiento entre «sindicato" y «partido", sino entre una tendencia y otra. En el mismo número - que publica también el texto de una conferencia dada por Luis Araquistain, el «teórico» de la radicalización caballerista, sobre «Contenido de la Revolución Española»-, Manuel Adame, en «Nuestra táctica. El proletariado en nuestra revolución popular», va un poco más lejos: a diferencia de lo ocurrido en otras revoluciones, en España no se ha modificado el aparato del Estado por «la inexistencia de un partido político de clase con visión clara del momento y capaz, por su formación doctrinal y por su arraigo en las masas, de tomar la determinación de destruir los viejos e inadecuados moldes del Estado capitalista». Ante ello se podría esperar que Adame concluyese, lógicamente, que habría que propiciar la constitución de ese partido, pero el PSOE estaba controlado por la otra tendencia. Por lo tanto, Adame invita a la clase obrera a unirse para llevar a cabo el siguiente programa: 1. Instauración de la dictadura democrática de los obreros y campesinos mantenida por los Comités de la Alianza (Obrera). 2. Mantener el contenido revolucionario del Ejército Popular. 3. Hacer intangibles las conquistas populares,

(27) Como es conocido, no se llegó a producir la visita de Largo y Avance fué suspendido y no reapareció hasta el 15 de febrero de 1938).

(28) Esa lucha estaba entablada entre tres concepciones políticas: «1. Una contrarrevolución empeñada en sostener el contenido feudal de la España oligárquica. 2. Una burguesía que, apoyada en los organismos del Estado, quiere afirmar el contenido democrático burgués de la República. 3. Un partido obrero que quiere superar la democracia burguesa para llegar a la estructuración de una República Socialista». Por supuesto, se advierte que «el partido comunista, por su propio designio, se sitúa en la defensa de la República democrático-burguesa». 
entregando la totalidad de la economía a los sindicatos obreros. 4. Transformar el estado capitalista en estado proletario, para propiciar la transición del capitalismo al socialismo.

En el número que aparece el 1-octubre-1937, Rodolfo Llopis continúa una serie de artículos que - con dificultades, pues la censura había prohibido su publicación en el número anterior de Spartacus y había causado bastantes estragos en el texto ( EEl compañero lector con su pensamiento complementará las lagunas que yo mismo intercale en el mío") - con el título de «Indiscreciones» venía publicando: plantea su visión parcial de la crisis de mayo, que centra, aunque apunta algunas otras causas menores (el exceso de ministros, el hecho de haber sido designados por sus partidos o sindicatos y no por el Presidente del Gobierno, lo que les llevaba a actuar siempre de forma partidista y a tener constantes enfrentamientos con los otros), en la actitud de los comunistas, que desataron una campaña contra Largo al negarse éste a la fusión y denunciar, por el contrario, el proselitismo del PCE en el frente y la retaguardia, la pasividad del PSOE y la evolución de la JSU: ante el temor de que tuviese éxito una ofensiva militar que preparaba Largo, se aceleró el cerco y se le hizo salir del Gobierno. En el mismo número, Ferrándiz Albors elogia extraordinariamente a Largo Caballero ("Los trabajadores se van dando cuenta de que él se situaba en la realidad que el tiempo y la lucha de clases exigian y exigen. Aún es tiempo de rectificar...») y Carlos Hernández Zancajo, en su artículo titulado «la tarea ingente del movimiento sindical español» defiende la participación sindical en los organismos del estado, al tiempo que atacaba «esa peligrosa tesis» que llevaba a hablar del pueblo, en lugar de los partidos y sindicatos. Otros dos ugetistas, Manuel Adame y Pascual Tomás advertían de los peligros de la nacionalización de las industrias de guerra y la amenaza de un capitalismo de estado si las industrias controladas por los sindicatos pasaban a ser monopolio de un estado que «no ha sido transformado de acuerdo con la realidad del país». El número aparecido el 1 de noviembre y compuesto, lógicamente, con relativa anticipación, continúa la defensa a ultranza de Largo Caballero, cuyo discurso de Madrid, en el cine Pardiñas, es calificado de "socialista clásico por su claridad»; también se analizan las reacciones de otros partidos y sindicatos ante el discurso, todas ellas contrarias (incluida la de la Ejecutiva del PSOE) salvo la de los libertarios. Se concluía -y no sin cierta razón- que «no podemos vivir supeditados a la defensa de una democracia burguesa que empieza por no interesar a los propios estados democráticos", por lo que de nada servían las concesiones a la burguesía y el estado "no puede frenar las aspiraciones de la clase que lo sostiene».

La misma resistencia caballerista a la ofensiva de la Ejecutiva que dirigía 
Lamoneda se advierte en la correspondencia entre la Ejecutiva Nacional y la FPS y las AS alicantinas. Uno de los partidarios de Prieto, Vicente Martínez Sansano, que presidia la FPS antes del Congreso de abril de 1937, se dirige a Lamoneda acompañando un recorte de Avance, correspondiente al 10 de septiembre de 1937, en el que se hacían públicas algunas decisiones de la Ejecutiva provincial (29) claramente contrarias a la disciplina del PSOE: en ese Pleno del Comité Provincial, celebrado el 8 de septiembre (30), el tema fundamental era la conveniencia o no de reanudar los comités de enlace con el PCE. En las discusiones, los delegados comparan a los comunistas con los jesuítas, exigen la disolución de la Federación Provincial Campesina como medida previa a toda colaboración con ellos, les acusan de actuar al dictado de Rusia ("y no vamos todos a ser rusos»), etc. Luis Deltell, un miembro de la Ejecutiva provincial al que le unía una buena amistad con Llopis, ataca a la Ejecutiva del PSOE (31) y concluye su intervención diciendo: «Debemos de cara a las masas ir a decirles la política podrida que está haciendo el PC en los frentes y la retaguardia; esto nos hará impopulares, pero en nuestra prensa, en el mitin, en la conferencia, donde sea, hay que arremeter con la politica del PC y contra el Partido mismo». Sin embargo, a la hora de la votación, fue el peso de la Ejecutiva el decisivo pues siete delegados comarcales votaron por reanudar los comités de enlace y seis en contra, mientras que de la Ejecutiva sólo uno votó a favor y cinco en contra, por lo que ganó la postura contraria a la reanudación de los comités, postura que, como se puede apreciar, no era tan unánime como, en sus relaciones con la Ejecutiva prietista, trataba de aparentar la ejecutiva de la FPS alicantina. Por ello, Martínez Sansano consideraba que «no habrá más remedio que aplicar una medida enérgica» y se ponía a disposición de la Ejecutiva "en espera de órdenes que reprueben de una vez este estado de indisciplina de unos malos socialistas".

Se asiste entonces a un nuevo periodo de enfrentamientos epistolares entre la FPS y la Ejecutiva Nacional: ésta insistía el 7 de octubre acusando

(29) No intervenir en los comités de enlace con el PC, porque no ha rectificado sus acusaciones contra Largo y además "se ha dedicado a calumniar a la Ejecutiva Provincial Socialista»; protestar por la actitud de la Ejecutiva nacional del PSOE al intervenir en el pleito interno de la UGT, lo que utiende a romper la disciplina interna de la central sindicalm; y adherirse a la Ejecutiva de la UGT que dirigía Largo Caballero por mantener «la tradición digna y consecuente y revolucionaria de nuestra gloriosa central sindicalm.

(30) Al que asisten delegados de Alicante, Alcoy, Callosa del Segura, Benisa, Polop, Villajoyosa, Novelda, Ibi, Almoradí, Orihuela, Elche, Jijona y Monóvar. No tienen representación Pego, Pedreguer, Villena, Torrevieja y Denia, mientras que Cocentaina envía un escrito oponiéndose a la reanudación de los comités de enlace.

(31) A la que, por cierto, en esa misma reunión, el delegado de Villajoyosa califica de ufacciosa». 
a la Ejecutiva caballerista de la UGT de hostilidad al gobierno, grave falta «como dirigentes y como socialistas", y advirtiendo que «la tolerancia de esta Ejecutiva con vuestra rebeldía tiene un límite», porque habían impuesto la ruptura del comité de enlace con el PCE contra el criterio de la mayoría de los vocales de la FPS, todo ello «por el compromiso de hacer una política de fracción». El 20 de octubre, contesta la FPS negando esas acusaciones (32) y asegurando que representaban el sentir inmensamente mayoritario de las Agrupaciones alicantinas que «algún día tendrán libertad para manifestarse ante quienes ahora se niegan a oírlas". Y el 28 de octubre se le comunican a la Ejecutiva nacional los acuerdos tomados por el Comité Provincial, que evidencian de nuevo el empecinamiento en su posición de los caballeristas alicantinos (33), quienes designaron una comisión para discutir sus opiniones con la Ejecutiva nacional en Valencia. El organismo que dirigía Lamoneda rechazó todas las acusaciones de los alicantinos, en carta enviada el 5 de noviembre: un Congreso socialista en las actuales circunstancias sería «ineficaz» y "perturbador» (34) y proponía como mejor remedio a la problemática interna del partido la disciplina. Agudamente, se señalaba de nuevo la inconsistencia de las argumentaciones caballeristas en relación con el PCE: vuestra actitud actual es contradictoria con vuestro estusiasmo anterior, pues fuistéis vosotros quienes abristéis a los comunistas las puertas de la UGT: « ¿Cómo se transformaron ahora, de repente, en perturbadores de la unidad antifascista quienes antes eran, según vuestro propio juicio, sus mejores servidores?». La Ejecutiva nacional recordaba también que el discurso de Largo había sido suspendido como el resto de los actos públicos y por decisión de un ministro socialista y concluía que, en definitiva, el problema básico en las relaciones entre ambos organismos era la lucha de tendencias: «Las quejas

(32) Al tiempo que comparaba el silencio de la Ejecutiva de Largo ante el gobierno de $\mathrm{Ne}$ grín con el que mantenía la Ejecutiva del PSOE en enero en relación con el gobierno de Largo Caballero.

(33) Ratificarse en la necesidad de un Congreso del PSOE; evitar que en la UGT actuasen quienes desde 1921 habian intentado corroer la unidad marxista, es decir, los comunistas; reunir un Congreso de la UGT; apoyar las medidas de Prieto sobre el Ejército; adherirse al gobierno de Negrin, pero lamentar las medidas tomadas, según ellos, por el Gobernador Civil, el comunista Monzón, para impedir la charla de Largo en Alicante; adherirse al discurso de Largo en Madrid, «reconociendo que el Partido Comunista es el mayor obstáculo que se opone a la unidad antifascista»; protestar de la suspensión de Avance y de que la Ejecutiva nacional hubiese hecho gestiones particulares con afiliados alicantinos «al margen de esta Federación» para "la designación de cargos en organismos oficiales".

(34) «Abrir una discusión ante (sic) nosotros en los presentes momentos sería debilitar el entusiasmo de los combatientes en los frentes. $Y$ nuestro deber, el de todos los socialistas, es el de fortalecer su moral en vez de debilitarlan. 
contra el Gobernador, la suspensión de AVANCE (35) y otras cosas más a que aludís se resolverían fácilmente en cuanto ese Comité, encuadrándose en la disciplina a que explícitamente le obliga su reglamento, actúe de acuerdo con la política que sigue esta Ejecutiva por mandato del Comité Nacionalm. La FPS - al margen de otras decisiones, que seguian mostrando todavía sus reticencias (36) - evidenciaba su extrañeza ante el último párrafo de la anterior comunicación de la Ejecutiva nacional, y ésta aclara todavía más su posición: ni nosotros ni el Gobierno podemos dar facilidades a quienes, más o menos veladamente, nos desobedecen. Por fin, el 28 de diciembre la Ejecutiva alicantina manifiesta que acepta todas las explicaciones dadas por la nacional porque «renunciamos a toda polémica, considerando superada la época según la cual (sic) vosotros distéis en llamar indisciplina de esta Federación, cosa que, a nuestro juicio, no existión.

Lo sucedido con Largo Caballero provocó también airadas cartas de muchas Agrupaciones alicantinas a la Ejecutiva nacional, no tan espontáneas como pudiera esperarse, pues muchas de ellas fueron fruto de la actividad de los parlamentarios alicantinos, pertenecientes a la tendencia caballerista. Así, la Agrupación de Sax pide en septiembre de 1937 información a Lamoneda sobre las causas de la detención de Largo Caballero, de lo que les ha informado una carta de Ginés Ganga Tremiño. Lamoneda lo desmiente, les recuerda que en el Gobierno hay socialistas y que se les debe de respaldar y lamenta que Ganga «vaya sembrando la discordia entre los socialistas». La Agrupación de Polop, que dirigía Joaquín Fuster -otro hombre claramente alineado en la tendencia de Largo Caballero, aunque enfrentado a otros compañeros de su comarca-, se mostró también muy activa en el apoyo a Caballero, a través del semanario local Octubre. La Agrupación de Monóvar denuncia a la Ejecutiva - que les pide «una información fiel»- que, en agosto de 1937, en un mitin sindical allí celebrado, tanto Villalta como Llopis hicieron valoraciones políticas contrarias a la Ejecutiva y a la unidad con los comunistas. La Agrupación de La Encina pide en noviembre de 1937 explicaciones a la Ejecutiva por el atropello cometido con Largo al residenciarlo en Valencia, según les comunica una carta firmada por Ganga: la Ejecutiva pide apo-

(35) Que fue levantada el 12 de noviembre, tras varias gestiones de la Ejecutiva alicantina ante Zugazagoitia; sin embargo, los obreros de Artes Gráficas alicantinos, influidos por los comunistas, boicoteaban la reaparición, por lo que se procedió a buscar operarios en Madrid: Avance no salió hasta febrero de 1938.

(36) Se comunica a primeros de noviembre a la nacional que se ha restablecido el comité de enlace con el PCE en la provincia, en prueba de buena voluntad, pero a mediados de mes apoyan a Prieto por los ataques de que fue objeto en el Pleno Nacional del PC, ataques que explicitamente niega la Ejecutiva nacional, que recuerda al mismo tiempo que Prieto es miembro de esa Ejecutiva a la que tanto critican los alicantinos. 
yo al Gobierno y critica a Ganga que, "por este hecho y por otros de no menor importancia, está francamente fuera de la disciplina del Partido». La Agrupación de Elche - alguna carta la firma Ramón Pastor-envia a la Ejecutiva y a la Federación Sindical Internacional varias comunicaciones en apoyo de Largo Caballero, alguna todavía a primeros de 1938, por lo que la Ejecutiva les advierte: «De nuevo os invitamos a prescindir de la política de fracción y a encuadrar vuestras actividades en las normas que en cada momento tome esta Ejecutiva como elemento rector del Partido" (37). El 16 de noviembre de 1937, la Agrupación de Denia informa a la Ejecutiva de que Ganga Tremiño «se está dedicando a visitar todas las Agrupaciones Socialistas de la provincia, cuyos comités reúne previamente, para exponerles las excelencias del largocaballerismo y la seguridad de que nuestra felicidad está en un Gobierno Largo Caballero" (38). En noviembre, la Agrupación de Benejama muestra su apoyo a Largo Caballero y lamenta la división existente, que sólo sirve para «deshonrar la sangre generosa de miles de camaradas que en nombre del Socialismo dieron su sangre en los frentes de batalla".

En 1938, y pese a las promesas de la FPS a finales del año anterior, no existía una auténtica unidad de criterio con la Ejecutiva nacional. En las cartas que entre ambos organismos se cruzan hay siempre reticencias y roces, algunos provocados por las medidas disciplinarias que tomó la Ejecutiva del PSOE con las Agrupaciones de Orihuela (39) y Bañeres (40), cuya actitud es, en gran medida, justificada por la Federación Provincial. Lógicamente, la prensa socialista alicantina insiste, en la medida de sus posibilidades, en sus posiciones: aparentemente, la Ejecutiva de Lamoneda y González Prieto había

(37) Carta de fecha 28-1-1938.

(38) Admitían, sin embargo, que en su actuación en Denia, Ganga había estado discreto, por conocer la fidelidad de la Agrupación local a la Ejecutiva, limitándose a echar las culpas de todo al PCE.

(39) Esta Agrupación comunicaba frecuentemente a la Ejecutiva nacional sus quejas por la actitud de los comunistas de la localidad, y en mayo de 1937 censuró la actitud de la Ejecutiva, porque debió de dar una enérgica contestación al PCE por su actitud de veto hacia unos compañeros socialistas, tal como ellos habían hecho a nivel local; en noviembre, se manifiestan a favor de la Ejecutiva de Largo en el pleito de la UGT y expresan su indignación ante lo ocurrido en octubre, enviando sus protestas al Presidente del Gobierno y al Ministro de la Gobernación. Ante ello, la Ejecutiva nacional les comunica que se han situado fuera del Partido. En enero de 1938 son readmitidos, tras haber rectificado «cuantos conceptos os expusimos en nuestra comunicación de 2 de noviembre pasado y que pudieron servir de base para nuestra expulsión».

(40) Una asamblea celebrada en septiembre de 1937 acordó manifestar su disconformidad con la actuación de la Ejecutiva nacional del PSOE en el pleito de la UGT, a cuya Ejecutiva dirigida por Largo pensaban seguir acatando sin aceptar orden alguna "que no venga refrendada por su secretario Largo Caballeron. Por todo ello, se le excluye del PSOE. Alegan los de Bañeres que se trata de opiniones en temas sindicales y por, tanto, no era lógica su exclusión del 
vencido en su enfrentamiento con los caballeristas, pero éstos conservaban sus bases. En Spartacus siguen los elogios a Largo Caballero y la constante actitud de crítica contra los comunistas, si bien utilizando generalmente la problemática internacional: los enfrentamientos entre socialistas y comunistas en Francia, el problema del ingreso de los Sindicatos Soviéticos en la Federación Sindical Internacional, etc. (41). En el n. ${ }^{\circ}$ 9, de marzo de 1938, la censura tacha por completo un editorial titulado "Autocrítica de Spartacus» y mutila otros textos de Ginés Ganga y Pascual Tomás: dividido el PSOE y en auge el PCE, en peligro por tanto la tradicional hegemonía socialista en el movimiento obrero español de signo marxista, no había más remedio que insistir en la gloriosa trayectoria del PSOE (42), renovar los tradicionales homenajes a Marx y a la Comuna, etc. Al propio tiempo, se anunciaba la aparición de un libro de Largo Caballero, Vísperas de la Revolución en unas «Ediciones Pablo Iglesias" que iban 'a propiciar los socialistas alicantinos.

La obsesión anticomunista continúa dominando la correspondencia entre la FPS y las AS alicantinas con la Ejecutiva nacional. En realidad, esa obsesión había comenzado como consecuencia del viraje de Largo Caballero, pero tenía antecedentes en el sector de Besteiro. En agosto de 1937 la Agrupación de Benejama pedía el envío de un orador para contrarrestar la campaña calumniosa de los comunistas en la localidad y lo mismo hace la de Dolores, porque allí habia muchos obreros desconcertados «por la política rastrera que lleva el PC»; en julio de 1937, los dirigentes locales de Pego comunican a Lamoneda sus recelos ante los comunistas y piden una campa-

partido, pero la Ejecutiva les recuerda que el Comité Nacional les encomendó en julio «cuidar de la orientación de los afiliados en el seno de la organización sindical» y que, además, «cuando se produce una división entre socialistas, lo natural es que sea el Partido el que indique una solución que restablezca la disciplina, sin la cual no hay organización posible», todo lo cual prueba cómo partido y sindicato se utilizaban en función de la tendencia defendida. Otras excusas y aparentes rectificaciones de la AS de Bañeres no convencen a la Ejecutiva, por cuanto, efectivamente, seguian manteniendo el espiritu de tendencia y «porque realizais una politica de fracción que personalizais en un compañero, cosa que estimamos contraria a la disciplina del Partido». La sanción fue anulada en abril de 1938.

(41) Por ejemplo, en el número 7, correspondiente a enero de 1938, se recoge un artículo de Edmond Lestaevel, «Cómo aplica el Partido Comunista Francés las enseñanzas de Lenin», que acababa con una cita de León Blum que, sin duda, hacían suya los socialistas alicantinos que editaban la revista: «El comunismo se desliza entre la sombra de las conspiraciones románticas, no por designio de su doctrina, sino por su organización. Su propaganda pública está al servicio de planes secretos que únicamente conocen los Jefes".

(42) «No hay una sola página de la Historia de España desde hace medio siglo hasta la fecha, que signifique una mejora económica y moral para el que trabaja, o la defensa de un postulado de justicia, en el cual no figure en primer término el PS rindiendo romanticamente el sacrificio - en vidas y libertades - de sus hombres más preclaros»: PASCUAL TOMAS, «... Y la independencia económica de los hombres». 
ña de propaganda del PSOE «para que no pueda ser el que, al calor de una unificación, se nos arrumbe como cosa gastada" (43). Las Agrupaciones alicantinas protestan por el excesivo predominio de los comunistas en la policía de varios pueblos (44), aunque se asegura, en un amplio informe enviado el 22-febrero-1938, que funciona muy bien el comité de enlace con el PCE: es decir, junto a la defensa teórica de la unidad y de la colaboración, el recelo ante el excesivo crecimiento de los comunistas: «Su influencia (del PSOE) en la provincia es grande, la mayor de todos los Partidos existentes, pues si bien el PC tiene en la actualidad una gran importancia numérica, por la bisoñez de la inmensa mayoría de sus radios, no han logrado penetrar en las masas obreras tan profundamente como nuestro Partido".

La situación del PSOE en Alicante pareció mejorar algo con la llegada al Gobierno Civil de Alicante del socialista Ricardo Mella, que envió en julio de 1938 un informe confidencial al Partido sobre la situación de la provincia de Alicante, que no dudaba en calificar de «lamentable», por cuanto se ha producido un "gravísimo error de partidos y sindicales al suministrar a troche y moche los carnets de afiliados a gentes que no nos es afecta y aún a verdaderos enemigos nuestros". (45) En un informe posterior, de septiembre, Mella se mostraba más optimista ( Creo que las cosas van bien para nuestro Partido. Se perdió mucho terreno durante la época del anterior Gobernador, pero ahora la gente nuestra se siente animada y alentada y trabaja bien») y afirmaba que, pese al predominio en la provincia de la tendencia caballerista, iba mejorando la disciplina y «se atiende, por lo menos desde que yo estoy aquí, las iniciativas de la Ejecutiva más francamente».

La crisis que en abril de 1938 provocó la salida de Prieto del Gobierno y que estallaría más dramáticamente, por lo que al PSOE se refiere, en la reunión del Comité Nacional en agosto - cuando Prieto se retiró tras haber pronunciado un feroz discurso contra Negrín y Lamoneda que, sin embargo, fueron apoyados por el Comité- dividió todavía más al PSOE al destrozar al sector reformista o «centrista». Los intentos de constituir una Ejecutiva Nacional en

(43) No hay que descartar en estas solicitudes de propaganda la intervención de los parlamentarios y el «aparato» provincial del Partido.

(44) En abril y mayo de 1938 la FPS alicantina envió varios informes a la Ejecutiva nacional sobre los desmanes de la censura y el excesivo papel que en la policia tenían los comunistas, algunos de los cuales tenían antecedentes derechistas.

(45) Aseguraba Mella que «el principio de autoridad es, con bastante frecuencia, desconocido y existen una serie de mandos y mandillos, de orden civil y militar, que sólo perjuicios, y grandes, producen a nuestra causa», por lo cual había tenido que enfrentarse con algún sector de la policía, como denunciaba Iniesta Cuquerella en cartas a la Ejecutiva Nacional, culpando de ello a los comunistas. 
la que, junto a Negrín y Lamoneda, se integrasen Besteiro, Prieto y Largo Caballero, para reunir así a todas las tendencias del PSOE, fracasaron rotundamente (46). Contrariamente a la interpretación tradicional, ni Negrín ni Lamoneda se entregaron de pies y manos a los comunistas: por citar un sólo ejemplo de su constante preocupación por preservar la identidad del PSOE, digamos que en septiembre de 1938 el Comité provincial socialista alicantino de enlace con el PCE consulta a la dirección del nacional del PSOE sobre si es correcto celebrar reuniones conjuntas en los pueblos entre ambos partidos para conmemorar determinadas fechas o discutir asuntos generales y el Comité Nacional recuerda su terminante oposición a tales asambleas. Sin embargo, Lamoneda y Negrín no veían otra política posible que la colaboración con los comunistas - a pesar de denunciar su proselitismo y de impedir la unidad con ellos, contraponiendo a las declaraciones públicas una actitud dilatoria en la práctica-. Sin embargo, amplios sectores del PSOE se lanzaron a una política abiertamente anticomunista, aún a riesgo de romper con la Ejecutiva del PSOE: en algunas provincias de la zona Centro-Sur se-llegó a crear una Organización Interprovincial con la misión prioritaria de recoger información sobre los abusos de los comunistas. Lamoneda consideraba que los problemas existentes entre socialistas y comunistas se resolverían mejor manteniendo los comités de enlace que suprimiéndolos, pero esto empujó a los centristas disidentes a buscar la unidad con los caballeristas: todos hicieron de Prieto una bandera y acabarían por coincidir con los besteiristas - que desde siempre habían manifestado su visceral anticomunismo- y por apoyar con la excusa de unos nombramientos militares, excusa que no deja de tener parecido con la utilizada por los nacionales para iniciar un alzamiento que venían preparando largo tiempo- el golpe de estado de Casado, que venía gestándose desde lejos y fue la consecuencia del clima de hostilidad hacia el PCE existente en las otras fuerzas políticas de la zona Centro-Sur y del cansancio general de la población frente a la guerra. (47)

La obsesión anticomunista no dejaba tampoco de estar en relación con el hecho de que, al ser el PCE el partido que con mayor vigor defendía la política de resistencia a ultranza, constituia el único obstáculo para intentar llegar a una paz con los franquistas, paz ansiada en muchos sectores de la España republicana, como consecuencia del cansancio ante la duración del

(46) Esta carta procede, como otras de Llopis, del Archivo Histórico Nacional, Sección Guerra Civil, en Salamanca.

(47) Obviamente, todas estas incidencias aumentaron la división del PSOE. Como ha comentado Antonio Elorza, «En torno a un debate clásico: guerra o revolución», en el citado libro colectivo Socialismo y guerra civil, «Un socialista se alzaba en armas contra un primer ministro socialista; no era fácil alcanzar mayor grado de desgarramiento en una formación política». 
conflicto bélico y del pesimismo reinante ante la evolución de la situación internacional. Por ello, menudeaban los ataques al PCE a niveles locales. En el número 11-12 de Spartacus, correspondiente a los meses de mayo y junio de 1938, el editorial («La unidad del proletariado») insiste en acusar a los comunistas, ahora adalides de la unidad, de haber provocado antes toda clase de escisiones: se contrapone a Stalin con Pablo Iglesias, se defiende de nuevo a Largo Caballero de los ataques de los comunistas - a cuyo "centralismo democrático", muy acertadamente, se acusaba de tener mucho de lo primero, pero poco de lo segundo- y se concluía en que la ansiada unidad estaba, en la realidad, muy lejos. De hecho, el Partido Comunista había crecido mucho y, como había afirmado Dolores Ibárruri en Valencia en junio de 1937, se presentaba ya como el gran Partido Revolucionario que necesitaba la clase obrera española. Se reiteraba, por tanto, ante esa amenaza, la gloriosa historia del PSOE, a la que se dedicaba gran parte del último número de Spartacus -correspondiente a julio-agosto de 1938 pero que, en realidad, apareció mucho después-, y su vocación revolucionaria: «EI PS se ha hecho consubstancial con los destinos de España desde ayer, desde hoy y para mañana. Quienes no sientan amor por España y quieran contribuir a su aniquilamiento, ya saben el camino a seguir: luchar contra el PSOE».

Por otra parte, los sectores enfrentados a la Ejecutiva del PSOE preferían el disimulo y la conspiración al enfrentamiento directo. Así se puede comprobar en unas cartas que se cruzan entre Rodolfo Llopis, el alicantino Luis Deltell, uno de sus hombres de confianza en la provincia, y la FPS : Déltell, miembro de la FPS alicantina, comunica por carta, en julio de 1938, a Llopis que le han llegado rumores de que «el viejo» (Largo Caballero, «cree que estamos desviados de nuestra consecuente posición. Está equivocado. Será por alguna cosa del periódico? Que no haga caso. Somos los de antes y estamos en donde estábamos. Dile que el día 18 de julio en los actos del Il aniversario, nosotros y los anarquistas le aludimos directamente cuando se hablaba de la organización y creación del Ejército Popular». Pese a ello, hay todavía Agrupaciones que se enfrentan directamente a la Ejecutiva nacional: así, la de Alcoy - que, en opinión de Rodolfo Llopis, se había caracterizado siempre por su sumisión a cualquier Ejecutiva - en una carta enviada el 7 de noviembre de 1938 a la Ejecutiva nacional, acusa directamente a Lamoneda de ser el principal culpable de la situación del PSOE, por su labor «de trampa y engaño» al ocupar un puesto de máxima confianza del Partido «en beneficio, no de éste, sino del Partido Comunista». Piden la dimisión de la Ejecutiva y envian copia de ello a Besteiro, Largo Caballero y Prieto. La Ejecutiva Nacional suspende en sus derechos a la Agrupación alcoyana "en tanto no rectifique oficialmente los conceptos injuriosos y atentatorios a la disciplina vertidos en 
dicha carta». (48).

A fines de 1938 la escisión en el seno del PSOE aumenta a pasos agigantados y la FPS de Alicante convoca un Pleno el 18 de diciembre, a pesar de la oposición de la Ejecutiva Nacional. Pese a ser refrendada su actuación por la asamblea, la Ejecutiva provincial dimite para «dar paso a una nueva situación que eliminara suspicacias con los organismos de la dirección nacional del Partido, suspicacias que redundaban en perjuicio de muchos afiliados, que aunque estaban atendidos por todos resultaba que en la práctica no los atendía nadie». (49) De todos modos, la composición de la nueva Ejecutiva no hizo variar la tendencia caballerista predominante en la provincia: cesaron Arraez, Deltell y Paquita Sánchez, continuaron Iniesta, Alted y Lizón, y entraron Luis Caballero, Juan Estevan Giménez y Enrique Ferrándiz Bellvert.

Naturalmente, Avance acogió con enorme alegría la noticia del golpe de Casado y evidenció de nuevo su actitud totalmente anticomunista. A niveles locales era dificil matizar tanto como lo hacía Rodolfo Llopis en su correspondencia de finales de 1938 con sus compañeros alicantinos al comentar la situación internacional. Llopis apreciaba la existencia en todo el mundo de una gran ofensiva anti-comunista, en la que los socialistas no podían embarcarse - «aunque sean ellos quienes con su conducta han provocado la reacción»porque «en cuanto los machaquen vendrán por nosotros. Aunque os confieso que no me siento con ánimo para defenderlos. También ellos, si pueden, con buenas o malas palabras, tratarán de machacarnos» (50). "Toda Europa se va complicando en la política anticomunista. A nosotros, nos guste o no nos guste, nos parezca justo o no, eso nos perjudica mientras sepan, como saben fuera de aquí que los comunistas tienen en sus manos los resortes que tienen en España» (51). "Ni podemos embarcarnos en la política anticomunista de los gobiernos europeos porque tras ellos iremos nosotros, ni nos sentimos con fuerza moral ni gusto para unir nuestra suerte a la de los comunistas".

Sin embargo, la eliminación del PCE de la vida política española no restañó las heridas internas del PSOE, aunque amplios sectores del Partido, seguidores tanto de Besteiro como de Caballero o Prieto, colaborasen con el

(48) Rodolfo Llopis, en carta a la FPS de 4-XII-1938, comenta que la reunión de la Ejecutiva en que se acordó apercibir a la Agrupación alcoyana sha sido muy dura pues la Agrupación de Alcoy, quizá sin proponerselo ha planteado un problema que está a la orden del día: la separación de Lamoneda».

(49) Avance, 21-diciembre-1938.

(50) Carta de 10-noviembre-1938, a la FPS.

(51) Carta de 4-XII-1938 a la FPS. Por ello pedian Llopis y otros socialistas reducir a los comunistas a sus legítimas posiciones y que «se forme un Gobierno de prestigiosas personas, muy representativas de los partidos politicos y que sean garantía para el pais y para el Extranjerow. 
Consejo Nacional de Defensa. Un último ejemplo de esa extraordinaria división interna -que, como es sabido, afectaría todavía muchos años más a los socialistas españoles, tanto en el exilio como en el interior- lo tenemos en el Pleno Provincial de la FPS alicantina que se celebra en Orán el 5 de julio de 1939: un informe de Llopis, que es enviado desde Albi, pinta un tenebroso cuadro de miserias humanas, acusaciones mutuas de cobardía y traición: la asamblea acuerda excluir de la Agrupación Socialista alicantina a Lizón y Escribano - que habian marchado a Colombia con fondos de la FPS para volver a sacar la revista Spartacus, cosa que les fue expresamente prohibida-, discute en torno a la forma en que se efectuó la evacuación desde el puerto de Alicante (52), y se llega incluso a los enfrentamientos físicos, que provocan la suspensión de la asamblea por unos días. Al final, se decide la disolución de la FPS. La impresión es de total caos.

(52) Se asegura que en el «Marítima» únicamente salió Rodriguez y que el resto de los miembros de la Ejecutiva lo hicieron desde Torrevieja, en barca. 